\title{
COMPRA-E-VENDA CONDICIONAL E "EMPTIO PERFECTA" EM TEMA DE RISCOS DA COISA VENDIDA ("PERICULUM REI VENDITAE")
}

CONDITIONAL SALE AND “EMPTIO PERFECTA” CONCERNING THE RISKS OF THE GOODS SOLD

(“PERICULUM REI VENDITAE")

Eduardo Cesar Silveira Marchi*

\begin{abstract}
Resumo:
Com base, em especial, na exegese de Paul. 33 ad ed., D. 18, 6, 8 pr., o Autor busca comprovar a proposta reconstrutiva de E. Seckel-E. Levy, secundados por M. Talamanca, conforme a qual teria sido a Escola dos Proculianos a adotar a regra de atribuição dos riscos ao comprador ("periculum est emptoris"), aplicando-a até mesmo nas hipóteses de caso fortuito ocorrido antes do verificar-se da condição.
\end{abstract}

Palavras-chaves: Compra-e-venda condicional. Riscos na compra-e-venda. "Periculum rei venditae".

\begin{abstract}
:
Based mostly upon the exegesis of Paul. 33 ad ed., D. 18, 6, 8 pr., the Author seeks to verify the theory proposed by E. Seckel-E. Levy, and seconded by M. Talamanca, according to which it was the Proculian School who adopted the rule that the purchaser must bear the risk that the object of sale might be lost, destroyed or damaged ("periculum est emptoris") and extended the application of such rule even in the case that an 'act of God' might occur before the satisfaction of the condition upon which the effectiveness of the contract was dependent.
\end{abstract}

Keywords: Conditional sale. Risks in contrate of sale. "Periculum rei venditae".

\section{Apresentação do problema}

A communis opinio - tanto a antiga quanto a atual ${ }^{1}$ - dentre os romanistas é a de que a regra romana de atribuição dos riscos pela perda ou deterioração fortuita da coisa vendida ao comprador ("periculum est emptoris") - e não ao vendedor, como no Direito moderno ("periculum est venditoris") ${ }^{2}$ - corresponda, de fato, ao regulamento vigente no Direito Romano, tanto clássico como justinianeu.

\footnotetext{
Professor Titular de Direito Romano e ex-Diretor da Faculdade de Direito da Universidade de São Paulo.

1 Cf., especialmente, dentre outros, KASER, M. Das römische Privatrecht I- das altrömische, das vorklassische um klassische Recht. 2. ed. München: Beck, 1971. p. 552.

2 No caso do Direito brasileiro, tal regra vem contemplada no art. 492, caput, do nosso atual Código Civil, ao dispor expressamente que "até o momento da tradição, os riscos correm por conta do vendedor". Este artigo, já presente no Código Civil revogado de 1916 (art. 1.127), inspirou-se fundamentalmente no Bürgerliches Gesetzbuch alemão. O BGB, em seu § 446 I 1, como regra geral, atribui ao vendedor, enquanto não entregue a coisa vendida, o periculum pelo perecimento acidental ou deterioração casual da mesma, ao declarar que "mit der Übergabe der verkauften Sache geht die Gefahr des zufälligen Unterganges und einer zufälligen Verschlechterung auf den Käufer über".
} 
Esta regra, presente em várias passagens do Corpus Iuris Civilis de Justiniano, sempre despertou, desde a Idade Média, grande perplexidade dentre os intérpretes, dada a sua aparente iniqüidade, ao penalizar o comprador mesmo estando ele ainda desprovido da propriedade, posse e guarda da coisa adquirida.

Mais justo pareceria, ao contrário, que fosse o vendedor, uma vez celebrada a compra-e-venda, a suportar os riscos, eis que ele, na qualidade de proprietário da coisa, ao gozar de todas as circunstâncias favoráveis disto decorrente (acrescimentos, produção de frutos, incrementos fluviais, etc.), deveria arcar, em contrapartida, com os eventos desfavoráveis (depreciação natural, deterioração fortuita, perecimento etc.).

Em face da presumida iniqüidade desta regra de atribuição dos riscos ao comprador, os romanos, segundo a doutrina dominante, teriam procurado mitigá-la ou amenizála, limitando-a, de um lado, a uma pretensa responsabilidade do vendedor pela "custodia" e, de outro, a uma suposta necessidade de ocorrência do estágio de venda "perfecta".

$\mathrm{O}$ interessante instituto jurídico da responsabilidade por custodia no Direito Romano (a chamada "Custodialehre" pelos alemães), desconhecido dos ordenamentos modernos ${ }^{3}$ corresponderia, segundo muitos autores, a uma verdadeira espécie de "responsabilidade objetiva", eis que o devedor respondia pelo inadimplemento independentemente de sua eventual conduta culposa.

Nas fontes romanas, a doutrina da "custodia" implicaria, a princípio e mais exatamente, não na responsabilidade ampla do devedor por qualquer tipo de caso fortuito ou de força maior, mas, de modo específico, pela vis minor, vale dizer, por furto (excluindo-se, portanto, o roubo ou subtração violenta), ou ainda, segundo alguns, por fato de terceiro.

Os casos seguros em Roma, segundo as fontes e os estudiosos, seriam os do comodatário (commodatarius), do tintureiro (fullo), do alfaiate (sarcinator), do transportador marítimo (nauta), do hoteleiro ou taberneiro (caupo) e do estalajadeiro (stabularius).

A eventual extensão deste tipo de responsabilidade objetiva também ao caso do vendedor (emptor), é, justamente, uma das principais dúvidas que se apresentam em relação ao tema do periculum rei venditae.

A doutrina dominante admite plenamente tal extensão: a regra romana de atribuição dos riscos ao comprador (periculum est emptoris) seria, pois, amenizada no Direito Romano clássico pela incidência, como se disse, desta pretensa responsabilidade por custodia do vendedor. ${ }^{4}$

Tal regra geral do Direito moderno costuma ser justificada com o recurso ao princípio "res perit domino", ou seja, a coisa perece com o proprietário, princípio este também expresso pelo adágio medieval "casum sentit dominus", isto é, o proprietário suporta o caso fortuito ou de força maior.

3 "Custódia", no Direito moderno, costuma indicar não a responsabilidade objetiva, como no Direito Romano clássico, mas a comum responsabilidade (subjetiva) por culpa: exige-se, pois, sempre o exame da diligência empregada pelo devedor.

4 Entende a communis opinio que no Direito Romano justinianeu a responsabilidade por custodia teria sido modificada, passando ela a ser equiparada a um tipo de responsabilidade subjetiva (culpa in custodiendo). 
Assim sendo, como corolário de tal amenização, uma vez celebrada uma comprae-venda, se a merx perisse ou se deteriorasse por vis maior, como na hipótese de um evento natural (v.g., uma enchente), os prejuízos seriam do comprador; se, todavia, a coisa vendida desaparecesse por vis minor (v.g., um furto), o dano caberia em contrapartida ao vendedor.

Com isto, a solução romana apresentar-se-ia menos iníqüa, dado o resultante maior equilíbrio entre as responsabilidades contrapostas do comprador e do vendedor.

A regra romana de atribuição de riscos na compra-e-venda, por outro lado, como se disse, seria mitigada, segundo a doutrina dominante, pela sua limitação temporal: não já desde o momento subseqüente à celebração do contrato, mas apenas a partir do seu "aperfeiçoamento" ou estágio de emptio perfecta.

Este é o assunto que agora nos interessa.

Segundo a communis opinio, em outros termos, dever-se-iam distinguir, com base no famoso fragmento de Paulo - 33 ad ed. prov., D. 18, 6, 8 pr. (“...et si id quod venierit appareat quid quale quantum sit, sit et pretium, et pure venit, perfecta es emptio..."), a ser examinado em seguida, os momentos de "conclusão" (ou "celebração") do contrato de compra-e-venda, e o de sua "perfeição" (ou "aperfeiçoamento").

A compra-e-venda, depois de "celebrada", apesar de já existente e eficaz sob vários aspectos, só produziria especificamente o efeito de transmissão do periculum ao comprador após alcançado o estágio de perfecta.

Tal estágio, ou seja, o "aperfeiçoamento" da emptio venditio, dependeria sempre ou do verificar-se de uma condição, como na compra-e-venda condicional, ou da individualização da coisa vendida, como no caso da compra-e-venda sujeita à contagem, medição e pesagem.

Diante desta communis opinio e de tal reconstrução histórico-dogmática acerca do periculum rei venditae, apresenta-se, todavia, uma importante corrente

Com isto, como bem nota ERNST, W. Periculum est emptoris. ZSS (Zeitschrift der Savigny-Stiftung für Rechtsgeschichte), n. 99, p. 217, 1982, a situação do comprador ter-se-ia agravado, passando ele a responder não-só por vis maior, quanto também por casus minor (furto). Já no Direito clássico, em contrapartida, a atribuição da originária responsabilidade por custodia ao vendedor limitaria, evidentemente, como já referido, os efeitos do princípio "periculum est emptoris", representando, pois, uma vantagem para o comprador, que só arcaria com os riscos decorrentes de vis maior (cf. THIELMANN, G. Traditio und Gefahrübergang. ZSS (Zeitschrift der Savigny-Stiftung für Rechtsgeschichte), n. 106, p. 294-295, 1989. 
minoritária, iniciada por C. Arnò ${ }^{5}$ e consolidada por F. Haymann, ${ }^{6}$ e que foi seguida por E. Betti $^{7}$ e, mais recentemente, de modo bastante articulado, por M. Talamanca. ${ }^{8}$

Nega-se, por esta doutrina minoritária, ao menos para o Direito Romano clássico - ou para um grupo de jurisconsultos daquela época, possivelmente pertencentes à Escola dos Sabinianos -, tanto a regra de atribuição dos riscos ao comprador quanto uma eventual responsabilidade por custodia do vendedor na compra-e-venda.

$\mathrm{O}$ dogma "periculum est emptoris" só teria sido alçado à qualidade de "princípio geral” no Direito Romano justinianeu.

Nos fragmentos concernentes a uma pretensa custodia (Gai. 10 ad. ed. prov., D. 18, 1, 35, 4, Paul. 5 ad Sab., D. 18, 6, 3, Paul., 3 epit. Alf., D. 18, 6, 15, 1, Nerat., 3 membr., D. 19, 1, 31, dentre outros), o vendedor, na verdade, seria responsabilizado, originariamente, não (objetivamente) por vis minor, mas (subjetivamente) por culpa ou negligência na guarda da coisa, ou ainda, fortius, por conduta dolosa.

Refuta-se, no mesmo sentido, a doutrina comum da emptio perfecta.

A compra-e-venda no Direito clássico, com base em textos como Paul. 33 ad ed., D. 18, 6, 8 pr., Gai., 10 ad. ed. prov., D. 18, 1, 35, 5 e 7 dentre outros, "aperfeiçoar-se-ia" independentemente de qualquer individualização da mercadoria por meio dos atos de contagem, medição ou pesagem, ou de qualquer subordinação ao verificar-se de uma condição.

A nossa "Arbeitshypothese"

Nossa hipótese de trabalho acompanha, em linhas gerais, esta última corrente minoritária, partindo-se da tese de que o dogma "periculum est emptoris" só teria alcançado a força de um "princípio geral" no Direito Romano justinianeu, como atestado expressamente em Inst. 3, 23, 3 .

\footnotetext{
Cf. La teorica del periculum rei venditae nel diritto romano classico. Giurisprudenza Italiana, n. 49, p. 209 e ss, 1987; Note minime sul § 3 Inst. 3,23, in AG (Archivio Giuridico) 62 (1899), p. 540 ss.; La costituzione ultima del Codice 'de periculo et commodo rei venditae' (Cod. 4.48.6), in Studi in onore di B. Brugi, Palermo, 1910, p. 151 ss.; e Sul c. 23 dei Fragmenta Vaticana (Cod. Iust. 4,48 'de periculo et commodo rei venditae' 5), in Memorie della R. Academia di Scienze Lettere ed Arti di Modena 9 (1910), p. 73 ss.

6 Cf. Textkritische Studien zum römischen Obligationenrecht. I- Über Haftung für custodia, in ZSS (Zeitschrift der Savigny-Stiftung für Rechtsgeschichte) 40 (1919), p. 167 ss.; II-"Periculum est emptoris", in ZSS (Zeitschrift der Savigny-Stiftung für Rechtsgeschichte) 41 (1920), p. 44 ss.; e Zur klassizität des "periculum emptoris", in ZSS (Zeitschrift der Savigny-Stiftung für Rechtsgeschichte) 48 (1928), p. 314 ss.

7 "Periculum"- Problemi del rischio contrattuale in diritto romano clássico e giustinianeo, in JUS 5 (1954), p. 333 ss. [=Studi in onore di P. de Francisci I, Milano, Giuffrè,1956, p. 131 ss.].

8 Cf. Vendita (diritto romano), in Enciclopedia del Diritto 46 (1993), p. 451 ss.; Considerazioni sul "periculum rei venditae", in Seminarios Complutenses de Derecho Romano 7 (1995), p. 217 ss.; e "Lex" ed "interpretatio" in Lab. 4, post. a. Iav. epit. D. 19,1,50, in Nozione formazione e interpretazione del diritto dall' età romana alle esperienze moderne - Ricerche dedicate al Professor Filippo Gallo, Napoli, Jovene, 1997, p. 353 ss.
} 
Quanto ao Direito Romano clássico, em contrapartida - acompanhando, especialmente, proposta preliminar de M. Talamanca ${ }^{9}$-, ter-se-ia apresentado, no tocante à duvidosa atribuição de riscos ou ao comprador ou ao vendedor, uma variedade de soluções.

Tal variedade dependeria, de um lado, do tipo de "fattispecie" e das circunstâncias nelas presentes (como, v.g., o tipo de poder ou guarda sobre a coisa vendida, as características específicas de cada merx, como vinho, dinheiro, imóvel, a efetivação ounão da traditio), e de outro lado, do posicionamento pessoal de cada jurisconsulto.

Nestes termos, dependendo de tais fatores, o ordenamento romano clássico, na forma de um sistema elástico, atribuiria o periculum ora ao comprador, ora ao vendedor.

Dentre os elementos que poderiam fundamentar, em não poucos fragmentos, esta variedade de soluções, pareceu-nos, a princípio, de grande relevância aquele representado pela efetivação ou não da traditio, isto é, da entrega ou-não da mercadoria - como, aliás, sempre sustentado pela doutrina minoritária de E. Betti, F. Haymann e sequazes.

Após confrontarmos tal possibilidade em relação ao problema do periculum na chamada dos aestimata, pelo exame de Ulp. 34 ad ed., D. 23, 2, 14 e Pomp. 14 ad Sab., D. $23,3,15,{ }^{10}$ bem como no tocante ao parecer de Alfeno, pelo estudo de dois importantes fragmentos de Paulo - 3 Alf. dig., D. 18, 6, 13 e 15 pr.-1 -, concernentes aos famosos casos dos lecti empti (camas compradas) destruídos por um Edil e da materia empta (madeira comprada) desaparecida por furto, ${ }^{11}$ pareceu-nos, até aqui, ter-se confirmado, com grande intensidade, o papel fundamental exercido pela traditio.

Passo seguinte, pois, e objeto do presente estudo, será a análise desta nossa "Arbeitshypothese" em relação ao principal fragmento em tema de venda condicional e emptio perfecta diante do problema do periculum, vale dizer, o famoso D. 18, 6, 8 pr., texto do jurista Paulo, extraído do livro 33 de sua obra de comentários ao Edito do Pretor.

3. A exegese de Paul. 33 ad ed., D. 18, 6, 8 pr.

Examinemos, portanto, o fragmento de Paulo que é considerado um dos textos-chave ${ }^{12}$ em tema de periculum emptoris na compilação justinianéia, amiúde arrolado pela communis opinio como prova inquestionável da regra romana de atribuição dos riscos ao comprador desde a época clássica.

D. 18, 6, 8 pr. (Paul. 3 ad ed.):

\footnotetext{
9 Vendita cit. (nota 8 supra) p. 451 e n. 1538.

${ }^{10}$ Cf. "Periculum rei venditae" e "periculum dotis aestimatae". Revista de Processo, 93, p. 125-150, 1999.

11 Cf. MARCHI, Eduardo Cesar Silveira Vita. Acerca da "traditio" no âmbito do problema dos riscos na comprae-venda - Os casos das "camas vendidas" (Paul., 3 Alf. dig., D. 18, 6, 13-15 pr.) e da "madeira comprada" (Paul., 3 Alf. dig., D. 18, 6, 15, 1). Revista da Faculdade de Direito da Universidade São Paulo, São Paulo, v. 99, p. 37-60, jan./dez. 2004.

12 Cf. TALAMANCA, M. Considerazioni. cit. (nota 8 supra), p. 241.
} 
Necessario sciendum est, quando perfecta sit emptio: tunc enim sciemus, cuius periculum sit: nam perfecta emptione periculum ad emptorem respiciet. Et si id quod venierit appareat quid quale quantum sit, sit et pretium, et pure venit, perfecta est emptio: quod si sub condicioneres venierit, si quidem defecerit condicio, nulla est emptio, sicut nec stipulatio: quod si exstiterit, Proculus et Octavenus emptoris esse periculum aiunt: idem Pomponius libro nono probat. Quod si pendente condicione emptor vel venditor decesserit, constat, si exstiterit condicio, heredes quoque obligatos esse quasi iam contracta emptione in praeteritum. Quod si pendente condicione res tradita sit, emptor non poterit eam usucapere pro emptore, et quod pretii solutum est repetetur et fructus medii temporis venditoris sunt (sicuti stipulationes et legata condicionalia peremuntur), si pendente condicione res exstincta fuerit: sane si exstet res, licet deterior effecta, potest dici esse damnum emptoris.

É necessário saber-se quando a compra torna-se perfeita, pois, assim então, saberemos de quem é o risco, já que, perfeita a compra, o risco caberá ao comprador. E assim, determinando-se claramente o objeto, sua qualidade e quantidade, bem como seu preço, e não estando o contrato sujeito a condição, torna-se perfeita a compra. Se, no entanto, a venda tiver sido ajustada sob condição, e esta não se realizar, a compra é nula, como também a estipulação. Caso, porém, a condição se tiver verificado, Próculo e Otaveno dizem que o risco é do comprador; assim igualmente entende Pompônio, no livro nono. Se, porém, pendente a condição, o comprador ou o vendedor tiver falecido, consta que, verificada a condição, também estarão obrigados os herdeiros, como se já anteriormente tivessem contraído a compra. Se ainda, pendente a condição, a coisa tiver sido entregue, o comprador não poderá usucapi-la na qualidade de comprador, bem como poderá exigir de volta o pagamento indevido do preço, cabendo ao vendedor, por fim, os frutos neste meio-tempo produzidos, da mesma forma como se extinguem as estipulações e legados condicionais quando, pendente a condição, a coisa venha a perecer. Se, todavia, $<$ ainda $>$ existir a coisa, mesmo que deteriorada, pode-se dizer que o comprador suportará o prejuízo.

A doutrina, de modo unânime - vale dizer, tanto a predominante, adepta do princípio periculum emptoris ante traditionem, quanto a minoritária, defensora da oposta regra periculum venditoris ante traditionem -, sempre considerou este texto manipulado pelos compiladores justinianeus.

Varia, contudo, a avaliação quanto ao significado e importância desta intervenção realizada pelos tribonianeus. 
Ao tempo da caça às interpolações, a communis opinio, apesar de lançar inúmeras suspeitas contra o texto, ${ }^{13}$ considerava-o, quanto à substância e soluções adotadas, de conteúdo clássico; a oposta doutrina minoritária, em contrapartida, diante de algumas expressas declarações ali constantes, era forçada a reconhecer uma intervenção radical dos justinianeus, que teriam interpolado inteiramente o fragmento, de maneira a introduzir o pretenso novo princípio do periculum emptoris. ${ }^{14}$

No estado atual de conhecimento, firmado o pressuposto metodológico da presunção de autenticidade das fontes, julga-se, com grande certeza, que o fragmento, apesar de clássico, teria sido recortado e abreviado pelos compiladores. ${ }^{15}$

As unânimes dúvidas quanto à manipulação do texto, tanto antigas quanto atuais, são bastante justificáveis, dadas as várias aparentes contradições e os inúmeros recortes ou raciocínios truncados nele presentes.

Uma destas aparentes contradições decorreria, por exemplo, da chave final do fragmento: "sane si exstet res, licet deterior effecta, potest dici esse damnum emptoris".

Parece evidente que, não verificada ainda a condição - e, portanto, ainda não perfecta a compra -, dever-se-ia concluir, dentro da lógica jurídica e do raciocínio trazidos no início do texto, que o periculum decorrente da deterioração da coisa vendida deveria caber ao vendedor. No entanto, surpreendentemente, declara-se que os riscos são atribuídos ao comprador: "potest dici esse damnum emptoris". ${ }^{16}$

${ }^{13}$ Cf., por exemplo, V. RUIZ, Arangio. La compravendita in diritto romano II. reimpr. Napoli: Jovene, 1956. p. 260-262, que levantava suspeitas contra grande parte do fragmento. Em face do caráter didático da frase inicial, deduzível das expressões "necessario sciendum est...tunc enim sciemus...", a doutrina, recordava o Autor, era unânime, incluindo até mesmo os maiores defensores da classicidade do princípio periculum est emptoris, ou seja, E. Seckel-E. Levy, em considerar bizantino este fragmento. Formalmente também suspeita, segundo V. ArangioRuiz, repetindo, como ele próprio informa, observação já feita por F. Schulz, in Kritische Vierteljahresschrift 50 (1912), p. 74, seria a frase "periculum ad emptorem respiciet". Dado o caráter estranhamente "oracolare" das palavras "si id quod venierit appareat quid quale quantum sit", onde, depois da promessa solene de uma aprofundada investigação, não se segue a esperada (e prometida) explicação mais aprofundada do quid, do quale e do quantum, dever-se-ia considerar tal frase, segundo ainda V. Arangio-Ruiz, La compravendita II cit. nesta nota, p. 260, como também não-clássica; este seu excessivo laconismo, decorrente da faltante explicação exigida, teria aliás induzido E. Seckel-E. Levy a concluir que o texto teria sido abreviado por juristas pós-clássicos ou talvez pelos compiladores, transformando-o em um mero índice. O emprego da simples expressão "si et pretium" para a enunciação das características da contraprestação tornaria o texto, nesta parte, incompreensível, e, portanto, suspeito, na opinião ainda de V. Arangio-Ruiz. Por fim, a pequena frase "et pure venit", ao não se coadunar, quanto ao modo verbal, com o "venierit" e com todos os conjuntivos que dele dependem, poderia induzir o intérprete, no entender do romanista (La compravendita II cit. nesta nota, pp. 260-261), a considerá-la certamente um acréscimo de segunda ou terceira mão; no entanto, malgrado estes indícios, tal suspeita seria contrastada pela importância revestida no texto por esta diminuta frase, à qual se liga toda a seguinte longa exposição, do pr. e até mesmo o parágrafo 1 ; de qualquer modo, todas as considerações no texto feitas sobre os princípios atinentes à compra-evenda condicional (considerações estas, aliás, observa ainda o Autor, onde a referência ao periculum emptoris" é apenas acidental), são estranhamente introduzidas por estas poucas palavras.

${ }^{14}$ Cf., neste sentido, HAYMANN, F. Textkritische. II cit. (nota 6 supra), p. 78 e ss.

${ }^{15}$ Cf., neste sentido, TALAMANCA, M. Considerazioni. cit. (nota 8 supra), p. 242: "Nelle condizioni in cui ci è pervenuto, il passo è stato, senza dubbio, largamente raccorciato".

${ }_{16}$ Justamente por conta desta contradição, parte dos intérpretes, no passado, como VASSALI, F. E. Dies vel condicio. BIDR 27 (1914), pp. 216 ss., costumava propor como inteiramente interpolado o arremate "sane 
Quanto aos possíveis recortes, sobressai-se o período correspondente à frase "quod si exstiterit, Proculus et Octavenus emptoris esse periculum aiunt: idem Pomponius libro nono probat": seria de se esperar que, em seguida ao exame da hipótese de ocorrência do evento condicional e, por conseqüência, da admissibilidade, segundo Próculo, Otaveno e Pompônio, do periculum emptoris, houvesse a declaração, em coerência com o contexto presente no parágrafo, de ser esta hipótese um caso em que a emptio torna-se perfecta. Tal conseqüente lógica declaração, porém, não aparece, trazendo, com isto, a fundada suspeita de que o texto original tenha sido mutilado pelos compiladores, com a eliminação de alguma parte. ${ }^{17}$

Concentremo-nos, porém, na exegese do fragmento quanto à sua substância e quanto aos raciocínios jurídicos nele expostos.

Da primeira parte do texto, em sua forma atual, deduz-se que, na doutrina de Paulo, a atribuição dos riscos ao comprador na compra-e-venda (periculum est emptoris) dependeria do "aperfeiçoamento" do contrato.

Requisitos para tal aperfeiçoamento (emptio perfecta) seriam: 1) a exata determinação do objeto do contrato quanto à sua identidade, qualidade e quantidade; 2) a fixação de um preço; e 3) a inexistência de cláusula condicional. ${ }^{18}$

No tocante a este terceiro requisito, perfecta, mais exatamente, segundo Paulo, seria tanto a compra-e-venda não sujeita a condicio (isto é, pura), como também a compra-e-venda condicional em seguida ao verificar-se da condição; imperfecta, em contrapartida, a compra-e-venda condicional pendente condicione.

Em seguida, apresenta-se a segunda parte do texto, bastante desarticulada e confusa. Nela são descritas diversas conseqüências jurídicas decorrentes da ocorrência ou-não do evento na compra-e-venda pendente condicione.

Este estilo assim "descuidado ou relaxado" não se constitui em indício a priori seguro de remanejamento do texto: seria ele característico não-só da literatura

si" rell. citado. Cuidando, mais recentemente, desta proposta, ERNST, W. Periculum. cit. (nota 4 supra), p. 224, dentro da sua hipótese de exegese - que examinaremos mais além -, em que a atribuição dos riscos ao comprador em caso de simples deterioração seria uma conseqüência natural da doutrina clássica dos atos jurídicos condicionais, entendia que tal frase final poderia ser eventualmente considerada um acréscimo pósclássico, dada a trivialidade de uma tal declaração. No entanto, concluía W. Ernst, mesmo que se tratasse de um acréscimo pós-clássico, corresponderia, de qualquer forma, ao exato pensamento da jurisprudência clássica. Esta aparente contradição era afastada por V. Arangio-Ruiz. La compravendita II cit. (nota 13 supra), p. 261 262, ao pressupor que a solução divergente, dada na parte final do texto, se aplicasse apenas ao caso de simples deterioração da coisa, e não ao de seu perecimento: "Ad esso si ritorna, abbandonando la terminologia del periculum per ricorrere a quella del damnum, solo nell'ultima frase, ove si rivela che, si vi fu non perimento ma semplice deteriorazione, questa sarà súbita dal compratore anche se avvenuta in pendenza della condizione (sempre, s'intende, che poi questa si sai verificata)".

17 Cf., neste sentido, V. Arangio-Ruiz, La compravendita II cit. (nota 13 supra), p. 261, e TALAMANCA, M. Considerazioni. cit. (nota 8 supra), p. 245.

${ }^{18}$ Cf. ERNST, W. Periculum. cit., (nota 4 supra), p. 225. 
casuística do período clássico, como também das obras de comentário ainda ao tempo de Ulpiano e de Paulo. ${ }^{19}$

Ainda quanto à segunda parte do texto, declara-se que, caso não ocorrida a condição, "nulla est emptio". Repete-se com esta frase, como bem observa V. ArangioRuiz, ${ }^{20}$ o princípio geral de que o negócio jurídico condicional é considerado como se nunca tivesse existido em caso de não verificação do evento. ${ }^{21}$

Em seguida, no fragmento, ainda em tema de compra-e-venda sujeita a cláusula condicional, Paulo cuida da hipótese em que, ao contrário da situação anterior ("si quidem defecerit condicio"), a condição tenha-se verificado ("quod si extiterit").

Neste caso de ocorrência da condicio, o jurista severiano cita o entendimento de Próculo e Otaveno, que julgavam, nesta situação, correr o risco por conta do comprador - "Proculus et Octavenus emptoris esse periculum aiunt" -, opinião, completa ele, também adotada por Pompônio - "idem Pomponius libro nono probat".

É este um dos pontos cruciais na exegese deste texto, e objeto de intensa controvérsia dentre os intérpretes e romanistas.

Ressalte-se, de início, que a doutrina é praticamente unânime em considerar mutilada esta parte do texto, em correspondência a um óbvio e manifesto remanejamento do texto em geral. ${ }^{22}$

Discute-se bastante se o suportar do risco por parte do comprador na hipótese de ocorrência do evento condicionado, opinião esta atribuída a Próculo, Otaveno e Pompônio, refira-se a casos de perecimento e infortúnios acontecidos antes ou depois da verificação da condicio: se antes, deveria caber o perigo, segundo a velha e tradicional interpretação deste fragmento, ao vendedor (periculum est venditoris); se depois, perfecionada a venda, ao comprador (periculum est emptoris).

${ }^{19}$ Cf. SCHULZ, F. Prinzipien des römischen Rechts. München: Duncker \& Humblot, 1934. p. 38 ss., e ERNST, W. Periculum. cit. (nota 4 supra), p. 226.

${ }^{20}$ La compravendita II cit. (nota 13 supra), p. 260-261.

${ }^{21}$ Supunham E. Seckel-E. Levy, Die Gefahrtragung beim Kauf im klassischen rômischen Recht, in ZSS (Zeitschrift der Savigny-Stiftung für Rechtsgeschichte) 47 (1927), p. 163, que Paulo, originariamente, nesta parte do texto (segundo eles, bastante interpolada), tivesse tratado apenas da hipótese de perecimento do objeto da venda antes do verificar-se da condição; com a assertiva "nulla est emptio" teria o jurista, por conseqüência, querido atribuir o prejuízo por tal perecimento ao vendedor. Contra tal parecer manifesta-se ERNST, W. Periculum. cit. (nota 4 supra), p. 227: pouco evidente nesta parte do texto seria uma eventual limitação ao caso de um precedente perecimento da coisa. Não se realizando a condição, raciocinaria Paulo - e, portanto, permanecendo imperfecta a venda -, não poderia, de qualquer modo, o vendedor exigir o pagamento do preço, independentemente do perecimento ou-não do objeto do contrato. $\mathrm{O}$ jurista, pois, ao declarar "nulla est emptio", não estaria especificamente se referindo à regra "periculum est venditoris", mas à situação jurídica em geral decorrente da não ocorrência da condição.

Neste aspecto, W. Ernst parece estar com a razão. Não há de fato referência, nesta segunda parte do texto, ao caso do perecimento da coisa.

${ }^{22}$ Neste sentido, segundo ERNST, W. Periculum. cit., (nota 4 supra), p. 228, n. 40, espúria seria pelo menos o "Rückbeziehungsgedanke quasi iam contracta emptione in praeteritum", como já anteriormente admitido, segundo ele, por W. Flume, G. Beseler e E. Seckel-E. Levy. 
Em conformidade com esta bastante antiga leitura, isto significaria que, segundo aqueles juristas citados, o comprador passaria a suportar os riscos apenas a partir - vale dizer, depois - da verificação do evento.

Próculo, Otaveno e Pompônio, portanto, confirmariam o entendimento de Paulo, expresso na parte inicial do texto, no sentido de que, perfecta a compra-e-venda, o risco passaria ao comprador.

Contra esta tradicional e antiga exegese se opuseram E. Seckel-E. Levy, ${ }^{23}$ acompanhados, quanto aos principais argumentos por ele trazidos, especialmente por W. Ernst $^{24}$ e M. Talamanca. ${ }^{25}$

Segundo E. Seckel-E. Levy, em face da admissão em geral, presente na parte inicial do passo, do princípio periculum est emptoris, ao se interpretar a parte do texto em discussão na forma proposta, dever-se-ia considerar uma completa "Banalität" a referência de Paulo ao parecer daqueles juristas, ou seja, em outros termos, uma declaração de obviedade absoluta inaceitável.

Seria evidente que o comprador, verificada a condição, passava a suportar os riscos, como Paulo já referira na introdução do texto. Correspondendo tal declaração a um princípio geral do Direito clássico, não haveria necessidade de Paulo, para sustentar seu parecer, dar-se ao trabalho de citar outros juristas.

Mais do que isso, se Paulo tivesse sentido, por hipótese, a necessidade de confirmar o seu entendimento, teria citado outros juristas, mas não especificamente Próculo, Otaveno e Pompônio.

Outra, então, segundo E. Seckel-E. Levy, deveria ser a chave de leitura.

Estes três juristas citados teriam querido dizer, na verdade, que o comprador responderia pelos riscos também já antes do verificar-se da condição, contanto que esta, evidentemente, viesse mais tarde de fato a ocorrer.

Verificada a condição, a regra periculum est emptoris teria, portanto, efeitos retroativos, abrangendo também o período de suspensão, ou seja, entre a conclusão do contrato e a ocorrência do evento condicional.

Diante, porém, da declaração seguinte de Paulo - "et quod pretii solutum est repetetur.....si pendente condicione res extincta fuerit" -, onde o jurista acolhe solução oposta, atribuindo o risco ao vendedor, dever-se-ia, por conseqüência, supor-se que tivesse havido, neste ponto, uma controvérsia dentre os juristas clássicos, cujo conteúdo mais completo teria sido cancelado pelos justinianeus, durante os trabalhos de compilação do texto original do jurista severiano.

\footnotetext{
${ }^{23}$ Die Gefahrtragung cit., (nota 21 supra), p. 170.

24 ERNST, W. Periculum. cit., (nota 4 supra), p. 227.

25 Vendita cit. (nota 8 supra), p. 454, e Considerazioni cit. (nota 8 supra), p. 242-250.
} 
A suposição de E. Seckel-E. Levy, portanto, seria a de que se tivesse tratado de uma "Schulenstreit" entre as Escolas dos Sabinianos e a dos Proculianos, com a opinião dos primeiros sendo adotada por Paulo, e a dos segundos, por aqueles três jurisconsultos citados.

Acolhida esta hipótese por parte da romanística mais recente, a maior dificuldade, em seguida, consistiria tanto na determinação do objeto da disputa, quanto na individualização dos eventuais juristas romanos que teriam participado desta controvérsia.

Segundo W. Ernst, ${ }^{26}$ não seria mais possível uma segura identificação dos jurisconsultos envolvidos em tal discussão, acolhendo também com reservas a sugestão de E. Seckel-E. Levy acerca da possível de uma "Schulenstreit" entre proculianos e sabinianos.

Em seu entender, repetindo opinião de W. Flume, objeto desta controvérsia, seria justamente a questão concernente à admissão dos efeitos retroativos do negócio condicional. Esta questão é referida por Gaio (Inst. 3,179), que atribuia a Servius Sulpicius a opinião (contrária à sua), segundo a qual a estipulação condicional deveria ser vista como válida já a partir de sua celebração, caso o evento viesse a se verificar.

Tal opinião, ainda segundo W. Ernst, teria sido acolhida por aqueles três juristas, que a teriam aplicado à "fattispecie" em exame, combinando-a com a aplicação do princípio geral "periculum est emptoris". ${ }^{27}$

Mais convincente, em nossa opinião, mostra-se a exegese de M. Talamanca, ${ }^{28}$ retomando parcialmente, em suas grandes linhas, a anterior proposta de E. Seckel-E. Levy.

No entender do Autor, argumentando também com base em Ner. 3 membr., D. 19, 1, 31 pr. e Cels. 3 dig., D. 12, 4, 16, poder-se-ia razoalvelmente conjeturar que os proculianos fossem desde o início adeptos, em geral, do "periculum emptoris", e que tivessem, tempos depois, agravado a posição do comprador - como comprovado pelo parecer de Próculo, seguido por Otaveno, e talvez também por Pompônio ${ }^{29}$ em D. $18,6,8$ pr. - , mediante a rigorosa aplicação dos efeitos retroativos em casos de venda condicional.

Quanto aos sabininanos, em contrapartida, pelo que se pode depreender do exame de textos como Jav. 7 ex Cass., D. 18, 6, 17, Iul. 15 dig., D. 18, 5, 5, 2, Ulp. 28 ad Sab., D. 18, 2, 2, 1, e D. 18, 2, 4, 1-2, Ulp. 29 ad Sab., D. 47, 2, 14, 1 e Gai. 10 ad ed.prov.,

${ }^{26}$ ERNST, W. Periculum. cit., (nota 4 supra), p. 228 e n. 41.

${ }^{27}$ Dever-se-ia, segundo ERNST, W. Periculum. cit., (nota 4 supra), p. 229, n. 44, excluir a possibilidade, sugerida por PETERS, F. Rücktrittsvorbehalte des römischen Kaufrechts. Köln-Wien: Böhlau, 1973. p. 147, de que esta decisão dos juristas citados tivesse dependido da aplicação da regra de atribuição de riscos de acordo com o princípio da tradição.

28 TALAMANCA, M. Considerazioni. cit., (nota 8 supra), p. 241-250 e 293-296.

${ }^{29}$ O jurista dos Antoninos, segundo TALAMANCA, M. Considerazioni. cit., (nota 8 supra), p. 242-243, n. 87, com base em Pomp.-Ulp. 28 ad Sab., D. 18, 2, 4 pr., repetindo proposta anterior de E. Seckel-E. Levy, Die Gefahrtragung cit. (nota 21 supra), p. 170,-, apesar de, no texto em exame dar a impressão de acompanhar Próculo e Otaveno, estaria mais próximo da posição de Paulo. 
D. 18, 1, 35, 5-7, há vários indícios, segundo M. Talamanca, que eles adotassem o oposto princípio do "periculum venditoris".

Teria sido então Paulo, ou também provavelmente parte da jurisprudência precedente, adepta do "periculum emptoris", o responsável pelo emprego generalizado do esquema da emptio perfecta como remédio para corrigir os resultados decorrentes da aplicação rígida dos efeitos retroativos em matéria de venda condicional.

Por fim, no Direito justinianeu, conclui M. Talamanca, dada a tendência de atribuir efeitos translativos ao simples contrato de compra-e-venda (como hoje, v.g, no Direito Civil francês e italiano), com a conseqüente aplicação do regime do commodum e do incommodum, os compiladores teriam acolhido de forma oficial o princípio "periculum est emptoris" (como expressamente declarado em Inst. 3, 23, 3).

De nossa parte, seguimos, em suas linhas gerais, como já dissemos, esta reconstrução histórico-dogmática proposta por M. Talamanca.

Acrescentamos, todavia, um ulterior aspecto.

Já vimos que, quanto à dicção desta parte do fragmento em exame, a referência à opinião de Próculo, Otaveno e Pompônio em favor da regra periculum est emptoris é apresentada de um modo bastante abrupto e repentino, logo em seguida à introdução das questões decorrentes da hipótese do verificar-se da condição - "quod si exstiterit". 30

Tal constatação poderia constituir-se, de fato, em um indício, como sempre reconhecido, de que alguma parte genuína do texto possa ter sido eliminada pelos compiladores.

Não é impossível, a nosso ver, que nesta eventual parte cancelada, ao se tratar da controvérsia entre proculianos e sabinianos, ou das opiniões divergentes entre juristas de uma ou outra Escola, tivesse sido feito referência, por parte daqueles últimos, adeptos do princípio "periculum est venditoris", ao elemento da traditio, como determinante na regra de atribuição dos riscos.

Esta hipótese encontraria certa comprovação na parte seguinte do texto, sobrevivida aos cortes procedidos pelos compiladores, em que justamente se faz alusão a determinada circunstância de fato - "quod si pendente condicione res tradita sint" - em que ocorre efetivamente a entrega da coisa vendida.

Concentremo-nos, em seguida, na parte final do texto.

Grande controvérsia reina na doutrina acerca da interpretação das frases de arremate deste fragmento de Paulo - "quod si pendente condicione ... potest dici esse damnum emptoris".

Nelas é declarado, em contradição com a parte inicial do fragmento, como já se disse acima, que, caso a condição ainda não se tivesse verificado ("quod si pendente

${ }^{30}$ Cf., neste sentido, ERNST, W. Periculum. cit., (nota 4 supra), p. 227. 
condicione"/"si pendente condicione"), o risco decorrente da mera deterioração da coisa caberia ao comprador, e não vendedor, como seria de se supor, eis que esta venda condicional ainda não era "perfecta".

$\mathrm{Na}$ discussão acerca do raciocínio exposto nesta parte final do texto, costumam os estudiosos proceder à sua exegese juntamente com outros dois fragmentos, que também tratam do problema no âmbito da venda condicional: Pap. 3 resp., Frag. Vat. 16 e Diocl. et Max. C. 4, 48, 5 (de 285 d.C.) [=Frag. Vat. 23].

Pap. 3 resp., Frag. Vat. 16:

Vino mutato periculum emptorem spectat, ${ }^{31}$ quamvis ante diem pretii solvendi vel condicionem emptionis impletam id evenerit. Quod si mille amphoras certo pretio ${ }^{32}$ corpore non demonstrato vini vendidit, nullum emptoris interea periculum erit.

O risco pela deterioração do vinho compete ao comprador, ainda que isto tenha ocorrido antes do dia do pagamento do preço ou do verificar-se da condição da venda. Porém, se mil ânforas de vinho, por um preço certo, e sem que fossem elas especificadas, ${ }^{33}$ tivessem sido vendidas, o risco, neste interim, não caberá ao comprador.

Nesta "fattispecie", Papiniano, ao atribuir o risco pelo estrago do vinho ao comprador, esclarece, de início, que tal decisão valeria ainda que diante de duas circunstâncias: não ter-se ainda vencido o prazo para o pagamento do preço e não terse tampouco verificada a condição. ${ }^{34}$ Em seguida, completa o jurisconsulto, caso, em

${ }_{31}$ Diante da extraordinária concisão e laconismo desta primeira frase do texto, onde falta uma especificação da situação de fato decidida por Papiniano, alguns intérpretes mais críticos, como nos informa ERNST, W. Periculum. cit., (nota 4 supra), p. 219, dentre os quais principalmente E. Seckel-E. Levy e G. Beseler, propuseram que o texto tivesse sido encurtado, com a eliminação de uma parte introdutória: "si quis vinum corpore demonstrato vendidit..." ou "si quis vinum omne, quod in cella esset, vendidit,...", segundo os primeiros, e "si is, qui vinum vendidit, certum vini corpus demonstravit,...", conforme aquele último.

${ }^{32}$ BESELER, G. Romanistische Studien - Die Gefahrtragung beim Kaufe im klassischen römischen Rechte. Le temps de la réflexion, n. 8, p. 284, 1927-1928, julgava espúria no texto esta expressa determinação do preço (propondo, pois, a sua eliminação), supondo que esta, em origem, estivesse tacitamente subentendida. Em relação ao problema do "periculum rei venditae", tal proposta não gerava, nem hoje gera, qualquer conseqüência de relevo.

${ }^{33}$ Segundo V. Arangio-Ruiz. La compravendita in diritto romano I, Napoli, 1954, p. 122-123, faz-se neste ponto do texto uma contraposição entre, de um lado, a venda de vinho cujo corpus demonstratum est, ou seja, por meio da separação, em um armazém, das ânforas a serem entregues (ou ainda, de outra forma possível, com a marcação ou assinalização das mesmas ânforas), com a sua colocação à disposição do comprador para a retirada), e, de outro - como no fragmento em exame -, a venda de uma quantidade de vinho corpore non demonstrato, isto é, onde aquela separação (ou marcação) não ocorre. No primeiro caso, concluia V. Arangio-Ruiz, Papiniano diria que o risco passaria imediatamente ao comprador; no segundo, continuaria a cargo do vendedor.

${ }^{34}$ Como bem assinala V. Arangio-Ruiz, La compravendita II cit. (nota 13 supra), p. 275, a condicio referida no texto é aquela verdadeira e própria cláusula condicional, em geral; não se trata, pois, nesta "fattispecie", de uma condição especificamente coligada com a determinação e controle do objeto da compra, através da mensura ou degustatio, como, por exemplo, aquela presente em Gai. 10 ad ed. prov., D. 18, 1, 35, 5. 


\section{contrapartida, se tratasse de periculum entendido como risco pelo perecimento das ânforas} de vinho, também não realizada condição, o prejuízo não mais caberia ao comprador, mas sim ao vendedor. ${ }^{35}$

\section{4, 48, 5 (Impp. Diocletianus et Maximianus AA. Aurelio Leontio):}

Cum speciem venditam per violentiam ignis absumptam dicas, si venditionem nulla condicio suspenderat, amissae rei periculum te non adstringit [a.285]..$^{36}$

Uma vez que dizes ter sido a espécie vendida consumida pela violência do fogo, caso nenhuma condição suspendesse a venda, não serás responsável pelo risco da coisa perecida.

Um certo Aurélio Leôncio, tendo vendido uma coisa que se destrói por um incêndio antes da entrega (pressupõe-se) ao comprador, consulta a Chancelaria dos

\footnotetext{
Da primeira situação descrita no texto, procurou Pн. Meylan, Inst. III,23,3 et $3^{a}$ et l'unification du regime des risques dans le contrat de vente par Justinien, in Atti Congresso Verona 3, Milano, 1948, pp. 403 ss., e "Periculum est emptoris"- Explication historique de l'art. 185, al. 1 C.C., in Vom Kauf nach schweizerischem Recht - Festschrift zum 70. Geburtstag von Prof. Dr. Th. Guhl, Zürich, 1950, pp. 32 ss., como nos informa V. Arangio-Ruiz, La compravendita II cit. (nota 13 supra), p. 275, deduzir uma tese geral para o nosso problema: tratando-se de res nec mancipi, com exceção do vinho, o periculum rei venditae correria por conta do vendedor até o ato do pagamento do preço, que coincidiria, por sua vez, com o da transferência da propriedade; a partir de então, passaria ao comprador. Contra tal tese insurge-se V. Arangio-Ruiz: ainda que se admitisse ter este único passo (dada a derivação de fonte pré-justinianéia) valor probatório contra as inúmeras passagens da compilação em sentido contrário, restaria o fato de que no mesmo não há qualquer referência à passagem da propriedade ou ao efetivo pagamento do preço. Papiniano, segundo o Autor, afirmaria simplesmente, neste seu parecer, que a determinação, quando da celebração da venda, de um prazo para o pagamento do preço não excluiria a passagem imediata (já a partir da celebração da venda) do periculum ao comprador; e, por fim, concluia, provindo o texto de um repertório de pareceres de Papiniano, seria "gratuita la supposizione che il responso sarebbe stato diverso se si fosse trattato di altro che di vino".

${ }^{35}$ É também grande a discussão na doutrina sobre se a "fattispecie" se refira a uma compra-e-venda de "limitada provisão" ou a uma compra e venda genérica. Em favor da primeira tese manifestam-se E. Seckel-E. Levy, Die Gefahrtragung cit. (nota 21 supra), p. 195 e ss., A. Bechmann, Der Kauf nach gemeinem Recht II, Erlangen, Deichert, 1884, p. 335, n.1, V. Arangio-Ruiz, La compravendita I cit. (nota 33 supra), p. 121 e ss., e W. Ernst, "Periculum" cit. (nota 4 supra), p. 231-232, n. 53; contra F. Haymann, Textkritische II cit. (nota 6 supra), p. 108 e ss., e, aparentemente, E. Rabel, Gefahrtragung beim Kauf, in ZSS (Zeitschrift der Savigny-Stiftung für Rechtsgeschichte) 42 (1921), p. 555, n. 2. No âmbito desta controvérsia, discute-se também bastante sobre o significado desta decisão de Papiniano para o nosso tema do periculum rei venditae. F. Haymann concluía que apenas em caso de mera compra e venda genérica o comprador não suportaria os riscos, enquanto que, em contrapartida, tratando-se de compra-e-venda de "limitada provisão", arcaria ele com os riscos decorrentes da deterioração do vinho. ERNST, W. Periculum. cit., (nota 4 supra), p. 231-232 e n. 53, por sua vez, julga tal argumentação inaceitável, já que a própria exigência, presente no texto, de uma individualização corporal do vinho induziria com toda evidência à conclusão de que Papiniano, em sua decisão, tratasse de uma comprae-venda "de limitada provisão". Por outro lado, um eventual emprego do parecer de Papiniano também em matéria de compra-e-venda genérica, como supõe F. Haymann, dependeria da admissão pelos clássicos de um tal tipo de contrato, tese refutada pela communis opinio.

${ }^{36}$ No passado, ao tempo da crítica interpolacionística, HAYMANN, F. Textkritische II. cit., (nota 6 supra), p. 147-148, por razões formais e de estilo, considerava este passo do Codex, correspondente a Frag. Vat. 23, não autêntico no período inserido entre "venditionem" e "te". Contra F. Haymann insurgiu-se SCHULZ, F. Kritische. cit., (nota 13 supra), p. 46, segundo o qual, em face de Frag. Vat. 23, não deveria haver qualquer dúvida quanto à genuinidade do complemento do texto contido em C. 4, 48, 5: "Die Vatikanenstelle ist zwar lückenhaft, aber doch so überliefert, daß über die Ergänzung kaum ein Zweifel sein kann”.
} 
Imperadores Diocleciano e Maximiano sobre se ele, vendedor do objeto desaparecido, deveria ou-não arcar com o prejuízo decorrente do contrato.

Responde-lhe aquela Chancelaria que, nestas circunstâncias, em não se tratando de uma compra-e-venda sujeita a condição, ele, vendedor, não seria responsável pelo perecimento da coisa, cabendo o risco, portanto, ao comprador - o qual continuaria obrigado a pagar o preço, ou, tendo-o já feito, não poderia pedir a restituição do valor.

Do exame da parte final do fragmento de Paulo, em conjunto com as duas fontes acima reproduzidas, W. Ernst, ${ }^{37}$ procura explicar a diferenciação feita por Paulo, presente em todas as três passagens, entre as hipóteses de perecimento total e simples deterioração do objeto na venda condicional: pendente condicione, vale dizer, enquanto não verificada a condição, em caso de perecimento total da coisa vendida, o vendedor suportaria o prejuízo ("periculum est venditoris"); já em caso de simples deterioração, o risco correria por conta do comprador ("periculum est emptoris").

Esta decisão de Paulo, cuja classicidade seria incontestável, não deveria, de modo algum, segundo W. Ernst, ser entendida como uma regra concernente à atribuição do periculum, ou ainda uma eventual repartição de riscos nas vendas sujeitas à cláusula condicional.

Neste sentido, ressalta - com razão, neste ponto - o Autor, Paulo não afirma jamais neste texto que o comprador "é exonerado do pagamento do preço" ou, mais do que isto, que "o risco corre por conta do vendedor"; o jurista diz apenas que "o pagamento do preço da compra será exigido de volta". ${ }^{38}$

Na verdade, o fundamento jurídico da solução de Paulo deveria ser buscado na doutrina clássica dos atos jurídicos condicionais. $\mathrm{O}$ verificar-se da condição nos atos jurídicos a ela sujeitos, diz W. Ernst, acolhendo como "Arbeitshypothese" os resultados alcançados por W. Flume, ${ }^{39}$ mais do que liberar os efeitos jurídicos suspensos daquele, como quer a doutrina tradicional, faria, pelo contrário, surgir o próprio ato, como se ele não tivesse existido anteriormente.

Assim, verificando-se a condição, se a coisa vendida não mais existisse, por ter anteriormente perecido, a emptio venditio deveria ser considerada como não ocorrida ou realizada, eis que um contrato de compra-e-venda sobre coisa inexistente não poderia ter sido concluído: nec emptio nec venditio sine re quae veneat potest intellegi (Pomp. 9 ad Sab., D.18, 1, 8 pr.).

Em outras palavras: o ato jurídico condicional não seria, como sempre se quis, um ato já existente, mas cujos efeitos jurídicos estão suspensos; ao contrário, enquanto não ocorrida a condição, o ato não seria considerado existente. Desta maneira,

\footnotetext{
${ }^{37}$ ERNST, W. Periculum. cit., (nota 4 supra), p. 221 e ss.

${ }^{38}$ Em terminologia moderna, completa ERNST, W. Periculum. cit., (nota 4 supra), p. 222, tratar-se-ia, nesta decisão, de "Rückgewährpflichten bezüglich rechtsgrundlos erhaltener Leistungen".

${ }^{39}$ Der bedingte Rechtsakt nach den Vorstellungen der römischen Klassiker, in ZSS 92 (1975), p. 96 ss.
} 
no caso tratado, se quando ocorrida a condição a coisa já tivesse perecido, o contrato não poderia surgir. Não surgindo, o prejuízo pelo perecimento é do proprietário, no caso o pretenso "vendedor", mas que, na verdade, nem chegou a ser um real vendedor.

A atribuição do prejuízo ao vendedor, neste caso, não decorreria, portanto, como quer parte da doutrina (como, v.g., V. Arangio-Ruiz), do fato de terem os clássicos considerado a hipótese de perecimento total pendente condicione uma exceção ao princípio "periculum est emptoris".

Assim como a atribuição do risco ao vendedor, em caso de perecimento total pendente condicione, não representaria uma adoção excepcional da regra "periculum est venditoris", da mesma forma, em contrapartida, o conferir do prejuízo ao comprador ("damnum emptoris") em caso de simples deterioração tampouco indicaria uma aplicação do princípio geral "periculum est emptoris".

A mera deterioração da objeto da venda pendente condicione não impediria o surgimento do contrato quando do verificar-se da condição, eis que a coisa, apesar de deteriorada, continuava existindo. A sobrevivência do objeto, ou, em outros termos, a sua concreta existência quando do verificar-se da condição, representaria, assim como para qualquer outro contrato, pressuposto básico para o gênesis da venda.

Em um tal sistema, por conseqüência, a eventual deterioração da coisa naquele intervalo de tempo não era obviamente levada em consideração (também pelo fato de que uma responsabilidade geral por vícios ocultos não era admitida pelo ius civile), suportando assim o comprador os parciais prejuízos.

Não se tratava pois de um eventual emprego do princípio "periculum est emptoris" já durante o tempo de suspensão do contrato.

Em conclusão: seria inexato, segundo W. Ernst, admitir-se, como já acima referido, que Paulo, em seu parecer, tivesse feito distinção entre o periculum do perecimento total e o periculum da parcial deterioração do objeto da venda condicional. ${ }^{40} \mathrm{~A}$ verdadeira "ratio decidendi" residiria no fato de que o perecimento da coisa vendida pendente condicione impedia o realizar-se do contrato, enquanto que a simples deterioração, não. ${ }^{41}$

De nossa parte, discordamos, neste ponto, dos resultados de W. Ernst.

A diversidade de soluções não dependeria de uma aplicação da doutrina clássica dos atos jurídicos condicionais, entendida pelo Autor, com base nos estudos de W. Flume, de forma diversa da tradicional.

\footnotetext{
${ }^{40}$ A diferenciação de soluções entre perecimento e deterioração do objeto da compra é também tratada por outros autores, como, v.g., F. Peters, Rücktrittsvorbehalte cit. (nota 27 supra), p.147, para quem o fundamento jurídico da distinção estaria na "Brauchbarkeit" (utilidade) da coisa. Contra ele insurge-se ERNST, W. Periculum. cit., (nota 4 supra), p. 223, n. 5, ressaltando como elemento determinante das decisões distintas (perecimento e deterioração) a sobrevivência ou-não do objeto: também uma coisa inteiramente inutilizável (depois da deterioração), mas ainda existente, poderia constituir-se como objeto lícito da compra e venda.

${ }^{41}$ Cf. ERNST, W. Periculum. cit., (nota 4 supra), p. 224: "der Untergang der Kaufsache das Zustandekommen des Kaufvertrages bei Bedingungseintritt hindert, die bloße Verschlechterung aber nicht".
} 
Neste específico aspecto, acompanhamos a communis opinio quanto ao entendimento tradicional do mecanismo de funcionamento do ato jurídico sujeito a condição suspensiva: ele é considerado existente (tanto que é parcialmente levado em consideração, como, v.g., na possibilidade de novação - Ulp. 7 disp., D. 46, 2, 14, 1 -, de remissão - Pomp. 15 ad Sab., D. 46, 3, 16 -, de transmissão da expectativa aos herdeiros etc.), mas tem seus efeitos jurídicos suspensos, enquanto não se verifica a condição.

Além da temeridade do acolhimento da tese de W. Flume como "Arbeitshypothese", a exegese de W. Ernst não poderia ser acolhida tendo em vista que as três fontes analisadas em conjunto não cuidam, a rigor, do mesmo tipo de "fattispecie".

Convém, por último, antes da conclusão, fazermos referência à reconstrução de F. Haymann, que, não-obstante a por assim dizer certa "caducidade metodológica" de parte de suas propostas, sempre esteve baseada em consistente trabalho de exegese aprofundada dos principais textos em tema de "periculum rei venditae", como o de Paulo ora em exame.

Este texto era elencado por F. Haymann ${ }^{42}$ dentre aqueles espúrios, onde o princípio "periculum est emptoris" viria acolhido.

Interpolada seria, em primeiro lugar, a expressão "emptio perfecta" no sentido empregado no fragmento, já que a mesma, em vária outras insuspeitadas passagens, significa "rechtsgültig zustandekommen" ou "vollziehn", ou seja, "passar a existir juridicamente". Além disso, um tão importante pressuposto em tema de atribuição de riscos na compra e venda, como este da emptio perfecta, não poderia ter sido esquecido por Paulo em Pauli Sent. 2, 31, 17 ou em Paul. 3 Alf. dig., D. 18, 6, 13 e 15; nestes textos, no entanto, o jurista não se manifesta de modo algum sobre este pressuposto, apesar de, dado o conteúdo genérico do ditado no primeiro ou o tipo especial de objeto da compra-evenda no segundo, ter tido ocasião para tal.

A proposta de conciliação entre Paul. 3 Alf. dig., D. 18,6,13 e 15 e o texto em exame, apresentada pela "Pandektenharmonistik", que sugere para a "fattispecie" das camas uma medição da quantidade ainda não realizada, seria, segundo o Autor, inaceitável. ${ }^{43}$

A composição bizantina do texto manifestar-se-ia também, continuava F. Haymann, na estranha combinação entre a parte inicial do fragmento e a sua seqüência: após um inicial tão "bombastisch" quanto importante anúncio do teorema da emptio perfecta, ao invés de se acentuar, em seguida - como teria feito um jurista clássico - o significado prático da regra, segue-se uma espécie de aula expositiva ou preleção didática sobre a compra-e-venda condicional, tratando-se do problema do periculum apenas de modo ocasional ou acidental.

\footnotetext{
${ }^{42}$ Textkritische II cit. (nota 6 supra), p. 78 e ss.

${ }^{43}$ Textkritische II cit. (nota 6 supra), p. 80.
} 
Por fim, o caráter não genuíno da "chiusa" ou fecho do fragmento decorreria, conforme o estudioso, ${ }^{44}$ não-só de razões formais, como - principalmente - substanciais: segundo Juliano e Paulo, como se deduz argumentando-se "e contrario" de Ulp. 28 ad Sab., D.18, 2, 2, 1, no caso do perecimento fortuito do objeto entregue antecipadamente pendente condicione ao comprador, o periculum permanecia a cargo do vendedor, passando ao comprador apenas quando mais tarde a condição viesse a se verificar.

No fecho de nosso texto, no entanto, estranhamente, em caso de perecimento pendente condicione do objeto já em posse do comprador, atribui-se ao mesmo, pura e simplesmente, o direito de exigir a restituição do preço, sem qualquer referência à ratio ou fundamento desta decisão.

Este "repetetur", portanto, concluia F. Haymann revela-se claramente como um "gesetzgeberischer Machtspruch", isto é, uma sentença ou decreto legislativo imposto pelos compiladores.

Esta solução justinianéia, que não leva em consideração a eventualidade de, mesmo perecendo a coisa, vir ou-não a condição a se verificar, presente no fecho do texto, corresponderia, segundo o Autor, ${ }^{45}$ a uma especial doutrina bizantina, conforme a qual o perecimento ou destruição do objeto imediato (ou seja, objeto da prestação) de uma obrigação condicional gerava necessariamente a extinção da relação jurídica.

Ao contrário do Direito clássico, que considerava o negócio condicional já eficaz a partir de sua celebração, ${ }^{46}$ na concepção bizantina o ato jurídico sujeito à condição suspensiva apenas tornava-se eficaz com o verificar-se da condição, de modo que os pressupostos de validade do negócio jurídico precisavam ser satisfeitos ainda no momento da "Bedigungseintritts"; assim sendo, perecendo o objeto, o negócio jurídico condicional seria considerado não realizado, como se desde o princípio tivesse sido prometida uma coisa não existente. ${ }^{47}$

Tal doutrina corresponderia perfeitamente à compra-e-venda na concepção do Direito privado grego, que não teria conhecido a "Konsensualkauf", mas apenas o "Realgeschäft": a simultaneidade de prestações nesta compra-e-venda real ou a vista não permitia, obviamente, que o negócio jurídico viesse a se aperfeiçoar ou existir se o objeto tivesse perecido precedentemente.

Os bizantinos, portanto, teriam, segundo o estudioso, não-só através de D. 18, 6, 8 pr., como também por meio especialmente de Ulp. 31 ad Sab., D. 23, 3, 10, 5 e

\footnotetext{
${ }_{44}$ Textkritische II cit. (nota 6 supra), p. 83-84.

${ }^{45}$ Textkritische II cit. (nota 6 supra), p. 84-99.

${ }^{46}$ No Direito clássico, pois, segundo HAYMANN, F. Textkritische. II cit. (nota 6 supra), p. 87-88, baseando-se especialmente em Venul. 3 stip., D. 46, 2, 31 pr., o perecimento do objeto de um negócio condicional não levava à extinção do vínculo jurídico.

${ }^{47}$ Cf. Textkritische II cit. (nota 6 supra), p. 85 e 94: “...daß die allgemeinen Voraussetzungen der Gültigkeit des bedingten Schuldvertrags noch im Moment des Bedigungseintritts gegeben sein müssen, daß das bedingte Rechtsgeschäft im Grund erst in diesem Zeitpunkt gültig geschlossen werde".
} 
Ulp. 7 disp., D. 46, 2, 14 pr., introduzido o novo dogma, pelo qual a não-sobrevivência do objeto de uma obrigação condicional impossibilitava a sua eficácia.

Já, em contrapartida, concluia F. Haymann, ${ }^{48}$ em caso de simples deterioração pendente condicione, pelo que se deduz da parte final de D. 18, 6, 8 pr., os justinianeus atribuiriam o prejuízo ao comprador.

A prova do caráter não-genuíno desta última solução poderia também derivar de Frag. Vat. 16.

Neste texto, a atribuição excepcional do periculum ao comprador, em caso de deterioração do vinho pendente condicione, derivaria de uma praxe ou costume derivado do Direito antigo, pelo qual, depois da degustatio, mas antes da traditio, atribuia-se o periculum ou riscos ao comprador; tal praxe teria, posteriormente, com base no caráter de bona fides do ato, se incorporado ao negócio jurídico de compra-e-venda de vinho.

Passemos às conclusões acerca do tema tratado.

\section{Conclusão}

Examinadas as principais propostas de reconstrução histórico-dogmática acerca da venda condicional e emptio perfecta em tema de periculum rei venditae, bem como, especialmente, as mais relevantes exegeses de Paul. 3 ad ed., D. 18, 6, 8 pr., parece-nos aceitável a hipótese lançada por M. Talamanca, fundada, em parte, em resultados anteriores alcançados por E. Seckel-E. Levy.

Segundo tal hipótese reconstrutiva, em época clássica, parte da jurisprudência, representada pelos jurisconsultos pertences à Escola dos Proculianos, acolhia o princípio "periculum est emptoris", fundando-o no regime do commodum e incommodum.

A confirmação desta tese viria da posição assumida, no fragmento examinado, pelos prudentes Próculo e Otaveno, seguidos, nesta específica "fattispecie", por Pompônio. Também Paulo optou pelo mesmo princípio, amenizando seu rigor, contudo, com a construção da figura da emptio perfecta.

Em contrapartida, há fortes indícios nas fontes (Jav. 7 ex Cass., D. 18, 6, 17, Iul. 15 dig., D. 18, 5, 5, 2, Ulp. 28 ad Sab., D. 18, 2, 2, 1, e D. 18, 2, 4, 1-2, Ulp. 29 ad Sab., D. 47, 2, 14, 1 e Gai. 10 ad ed. prov., D. 18, 1, 35, 5-7) - ainda sujeitos a confirmação - de que os juristas da Escola dos Sabininianos tivessem optado pelo princípio oposto, isto é, "periculum est venditoris".

Quando, por fim, ao Direito justinianeu, não pode haver dúvidas da prevalência da primeira solução, defendida pelos proculianos, que atribui os riscos pela

\footnotetext{
${ }^{48}$ Cf. Textkritische II cit. (nota 6 supra), p. 98-99: "Daß gerade Papinian ein allgemeiner Rechtssatz, wonach der Käufer beim bedingten Kauf pendente condicione jedes periculum deteriorationis zu tragen habe, unbekannt war, legt auch sein Ausspruch in fragmenta Vaticana 16 (Pap. 482 Lenel) nahe".
} 
perda fortuita da coisa vendida ao comprador desde a celebração da emptio venditio. Assim sendo, o princípio "periculum est emptoris" ter-se-ia tornado, claramente, uma espécie de "dogma bizantino".

Em relação à nossa "Arbeitshypothese", ao menos quanto a este fragmento de Paulo estudado, 3 ad ed., D. 18, 6, 8 pr., o elemento da traditio, da maneira como o texto chegou até nós (vale dizer, encurtado e remanejado pelos justinianeus) parece não exercer qualquer papel de relevância.

Todavia, não é inteiramente improvável que em alguma parte original do texto de Paulo, mutilada pelos compiladores, houvesse alguma referência à doutrina oposta, acolhida pelos sabinianos, do "periculum est venditoris", talvez com menção à figura da traditio.

Tanto esta possibilidade, quanto, em termos mais gerais, a proposta de reconstrução histórido-dogmática de $\mathrm{M}$. Talamanca, por nós ora aceita, acerca do problema dos riscos na compara-e-venda romana, dependem, porém, como já se disse, de comprovações posteriores, por meio da exegese das demais fontes relativas ao tema tratado.

A vexata quaestio acerca do periculum rei venditae continua, portanto, em aberto.

São Paulo, março de 2008. 